\title{
Minimizing injection pain in local anesthesia
}

\author{
Robert Strazar BSc, Don Lalonde MD
}

\begin{abstract}
A smaller diameter of needle and warming the injection solution can reduce pain

The choice of needle diameter can influence the pain felt by the patient. A well-designed randomized controlled trial (RCT) showed an inverse relation between needle diameter and pain. ${ }^{1}$ A smaller needle also forces the injector to slow down, minimizing pain from volume expansion. A longer needle (e.g., 1 1/4" v. 5/8") is useful for injecting larger areas. In addition, warming the solution results in a less painful injection. ${ }^{2}$
\end{abstract}

\section{A pause allows the anesthetic to alle-} viate the initial pain of the injection*

The first $0.2-0.5$ millilitres should be injected subdermally, rather than intradermally, followed by a pause. This pause allows the local anesthetic to alleviate the pain caused by the needle being in the skin. More anesthetic can then be injected slowly, before changing the needle's angle and moving laterally. When properly done, a large wheal will be seen beneath the skin, and the patient will not have felt any pain since the first poke. ${ }^{5}$ It is important to ask your patients to tell you if they feel any further pain during the injection.

\footnotetext{
*These recommendations are based on feedback we have received from thousands of patients concerning pain on injection.
}

CMAJ invites submissions to "Five things to know about ..." Submit manuscripts online at http://mc.manuscriptcentral.com/cmaj

\section{Buffering lidocaine with sodium bi- carbonate can minimize the typical burning sensation}

With an acidic $\mathrm{pH}$ of 4.7 , lidocaine can cause an unpleasant burning sensation. A Cochrane meta-analysis of several RCTs determined that the addition of sodium bicarbonate (10:1 lidocaine: sodium bicarbonate $\left[8.4 \% \mathrm{NaHCO}_{3}\right]$ ) can considerably minimize pain. ${ }^{3}$ When buffering the anesthetic, it is worth noting that syringes can hold a higher volume than indicated (e.g., a 10-millilitre syringe can actually hold 11 millilitres).

\section{Keep some visible anesthetic ahead of the needle's tip*}

Almost always, pain after the first poke is caused by the needle tip hitting nerves that have not yet been anesthetized. When moving laterally beneath the skin, it is important to keep five millimetres of palpable or visible local anesthetic ahead of the tip. This technique anesthetizes the subdermal nerve endings and should make a pain-free experience more likely for the patient. ${ }^{6}$
The initial poke should be perpendicular to the skin, not angled

Sensory nerve endings in the skin branch out like a tree. By penetrating at an angle of $90^{\circ}$, the needle intersects fewer nerves (Appendix 1, available at www.cmaj.ca/lookup /suppl/doi:10.1503/cmaj.111780//DC1. One RCT involving more than 60 patients showed that there was significantly less pain with injections done at $90^{\circ}$ than those done at $45^{\circ} .4$

\section{References}

1. Arendt-Nielsen L, Egekvist H, Bjerring P. Pain following controlled cutaneous insertion of needles. Somatosens Mot Res 2006;23:37-43.

2. Hogan ME, van der Vaart S, Perampaladas K, et al. Systematic review and meta-analysis of the effect of warming local anesthetics on injection pain. Ann Emerg Med 2011;58:86-98.

3. Cepeda MS, Tzortzopoulou A, Thackrey M, et al. Adjusting the $\mathrm{pH}$ of lidocaine for reducing pain on injection. Cochrane Database Syst Rev 2010; (12):CD006581.

4. Martires K, Bordeaux J. Reducing the pain of lidocaine administration by controlling angle of injection. J Am Acad Dermatol 2011 (Suppl 1);64: AB167.

5. Lalonde DH. "Hole-in-one" local anesthesia for wide awake carpal tunnel surgery. Plast Reconstr Surg 2010;126:1642-4.

6. Mustoe TA, Buck DW II, Lalonde DH. The safe management of anesthesia, sedation and pain in plastic surgery. Plast Reconstr Surg 2010;126: $165 \mathrm{e}-76 \mathrm{e}$.

Competing interests: Don Lalonde is a consultant for ASSI Instruments. No other competing interests were declared.

This article has been peer reviewed.

Affiliations: From the Michael G. Degroote School of Medicine (Strazar), McMaster University, Hamilton, Ont.; and the Division of Plastic and Reconstructive Surgery (Lalonde), Dalhousie University, Saint John, NB

Correspondence to: Don Lalonde, drdonlalonde @nb.aibn.com 